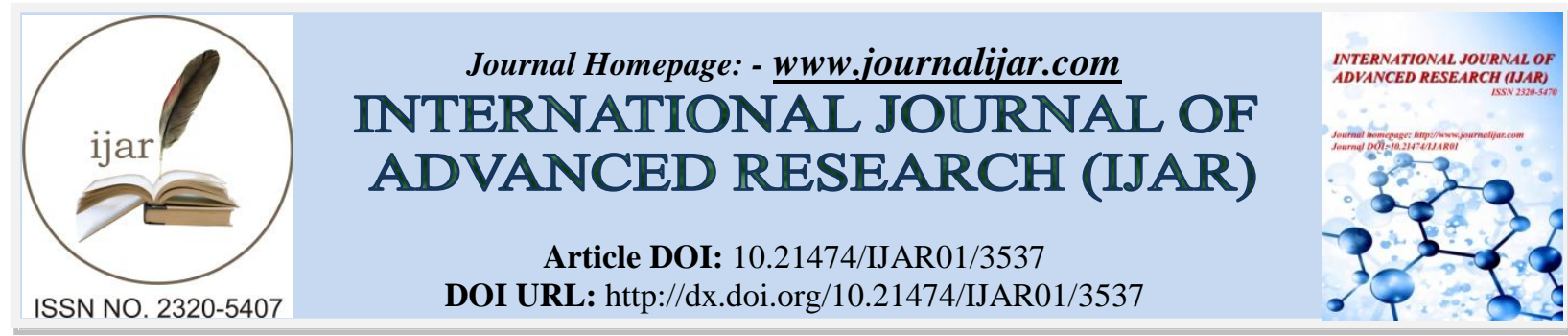

RESEARCH ARTICLE

\title{
IMPACT OF RISK-RETURN ANALYSIS ON STOCK FUTURES AND OPTIONS TRADING IN INDIAN EQUITY DERIVATIVES MARKET WITH SPECIAL REFERENCE TO NSE.
}

Ramasamy. $V^{1}$ and Dr. G. Prabakaran ${ }^{2}$.

1. Ph.D Research Scholar, Management, Bharathiar University, Coimbatore, Tamilnadu.

2. Assistant Professor, Government Arts College Dharmapuri, Tamilnadu.

\section{Manuscript Info}

Manuscript History

Received: 16 January 2017

Final Accepted: 15 February 2017

Published: March 2017

Key words:-

Futures, Call and Put option, Closing price, Strike price, Bullish and Bearish Market, Risk and Return.

\begin{abstract}
Futures \& options is one of the most important segments in derivatives market in India. Financial derivatives have emerged as one of the largest market of the world during the past two decades in terms of trading volume, number of index and stock options available for trading, participation of investors in derivatives market. It is also observed that investors are showing lot of interest in the derivatives market. However, investors have lost lot of money in the derivatives market due to lack of knowledge about the product and investment strategies etc. The risk involved in futures and options trading can be minimized / return on futures and options trading can be improvised through designing suitable investment strategies. So, investor need to develop risk management as well as risk analysis tool which is the key to limiting futures and options risk/maximizing profit. The derivatives contract is standardized contract. In India, the BSE Sensex and Nifty50 are the popular indices on futures and options trading. The everyday price changes will occur on stock index futures and options. Some of the major factors such as weather, war, Debt, refugee displacement, land reclamation and micro \& macro economic factors will affect the index prices. So, this study challenge to test the precariousness of stock index prices in Indian Derivatives market and also this study have to focus on software industry Infosys \& TCS during the period of April to June 2016.
\end{abstract}

Copy Right, IJAR, 2017,. All rights reserved.

\section{Introduction:-}

The futures and options market have been the fastest growing segment of the securities industry. With this rapid growth has come to debate over the purpose served by futures and options in the capital markets. As we see it, the principal function of futures and options is to provide a significant expansion of the patterns of portfolio returns available to investors. Such expansions make investors better off and add to the liquidity and efficiency of the capital markets.

The emergence of the market for derivative products are forward, future and option are traded in the derivatives market. Comparing to stock market, derivatives markets are more risky because everything should be in a contract format. Derivatives are risk management instruments, which derive their value from an underlying asset. Banks,

Corresponding Author:- Ramasamy.V. 
Securities firms, companies and investors to hedge risks, to gain access to cheaper money and to make profit, use derivatives. Derivatives are likely to grow even at a faster rate in the years to come.

Price fluctuations make it hard for businesses to estimate their future production costs and revenues. Derivative securities provide them a valuable set of tools for managing this risk. This article describes the progress of Indian derivatives markets, the popular derivatives instruments, and the main users of derivatives in India.

\section{Introduction to Derivatives Market in India:-}

Derivative trading in India takes can place either on a separate and independent Derivative Exchange or on a separate segment of an existing Stock Exchange. Derivative segment function as a Self-Regulatory Organisation (SRO) and SEBI acts as the oversight regulator. By their very nature, the financial markets are marked by a very high degree of volatility. Through the use of derivative products, it is possible to partially or fully transfer price risks by locking in asset prices. As instruments of risk management, these generally do not influence the fluctuations in the underlying asset prices. However, by locking in asset prices, derivative products minimize the impact of fluctuations in asset prices on the profitability and cash flow situation of risk-averse investors. In the last decade, many emerging and transition economies have started introducing derivative contracts.

\section{National Stock Exchange of India Ltd:-}

The National Stock Exchange of India Limited (NSE) commenced trading in derivatives with the launch of index futures on June 12, 2000. The futures contracts are based on the popular benchmark Nifty 50 Index. The Exchange introduced trading in Index Options (also based on Nifty 50) on June 4, 2001. NSE also became the first exchange to launch trading in options on individual securities from July 2, 2001. Futures on individual securities were introduced on November 9, 2001. Futures and Options on individual securities are available on 173 securities stipulated by SEBI. The Exchange has also introduced trading in Futures and Options contracts based on Nifty IT, Nifty Bank, and Nifty Midcap 50, Nifty Infrastructure, Nifty PSE indices. This section provides you with an insight into the derivatives segment of NSE. Real-time quotes and information regarding derivative products, trading systems \& processes, clearing and settlement, risk management, statistics etc. are available here. Today NSE's share to the total equity market turnover in India averages around $72 \%$ whereas; in the futures and options market share is around $99 \%$.

\section{Basics of Equity Derivatives:-}

According to the Securities Contract Regulation Act, (1956) the term Derivative is a contract or a product whose value is derived from value of some other asset known as underlying.

Equity derivative is a class of derivatives whose value is at least partly derived from one or more underlying equity securities. Options and futures are by far the most common equity derivatives. It provides you with an insight into the daily activities of the equity derivatives market segment on NSE. Two major products under Equity derivatives are Futures and Options, which are available on Indices and Stocks.

\section{Derivatives Product:-}

Index Futures: The contracts are traded on an Index futures or financial index. For each index there may be a different multiple for determining the price of the futures contract.

Index Option:- These options have the index as the underlying asset. In India, Index options are European option. For example options on Nifty, Sensex, etc.

Stock Futures:- Stock futures are agreements to buy or sell a specified stock, i.e., the equity share of a specified company, in the future at a specified price.

Stock option: These options have individual stocks as the underlying asset. For example, option on ONGC, NTPC etc.

Futures Contract:- A future contract is an agreement between two parties to buy or sell an asset at a certain time in the future at a certain price. Futures contracts are special types of forward contract in the sense that the former are standardized exchange- traded contracts. 


\section{Options Contract:-}

An option represents the right to buy or sell a security or other asset during a given time for a specified price. Options are of two types:

Call option: It gives the buyer the right but not the obligation to buy a given quantity of the underlying asset.

Put option: It gives the buyer the right, but not the obligation to sell a given quantity of the underlying asset.

European option: The owner of such option can exercise his right only on the expiry date/day of the contract. In India, Index options are European.

Positions in derivatives market As a market participant, you will always deal with certain terms like long, short and open positions in the market. Let us understand the meanings of commonly used terms:

Long Position Outstanding/ unsettled buy position in a contract is called "Long Position".

Short Position Outstanding/ unsettled sell position in a contract is called "Short Position".

Open position Outstanding/ unsettled either long (buy) or short (sell) position in various derivative contracts is called "Open Position".

The Derrivatives Market Participants:-

There are broadly three types of participants in the derivatives market - hedgers, traders (also called speculators) and arbitrageurs. An individual may play different roles in different market circumstances.

Hedgers They face risk associated with the prices of underlying assets and use derivatives to reduce their risk. They always wanted to reduce their investment risk.

Speculators They try to predict the future movements in prices of underlying assets and based on the view, take positions in derivative contracts. Derivatives are preferred over underlying asset for speculation purpose, as they offer leverage, are less expensive (cost of transaction is generally lower than that of the underlying) and are faster to execute in size (high volumes market). They are accepting their investment risk with view to more return.

Arbitrageurs Arbitrage is a deal that produces profit by exploiting a price difference in a product in two different markets. Arbitrage originates when a trader purchases an asset cheaply in one location and simultaneously arranges to sell it at a higher price in another location. Such opportunities are unlikely to persist for very long, since arbitrageurs would rush in to these transactions, thus closing the price gap at different locations. They don't want to take risk and always play with safe.

\section{Review Of Literature:-}

Phil Holmes (2006), Stock index future hedging: Hedge ratio estimation, duration effects, expiration effects and Hedge ratio stability this study focused the impact of hedge duration, and the time of expiration and hedge ratio stability over the study period and it helps to find with the help of some statistical tools like OLS, ECM, Risk \& Return Analysis, Descriptive Statement and GARCH models.

Antonios Antoniou and Phil Holmes (2000), Futures trading, information and spot price volatility: evidence for the FTSE-100 stock index futures contract using GARCH This paper examines the impact of trading in the FTSE100 Stock Index Futures on the volatility of the spot market. It ensures that the relationship between information and volatility of the spot and future with the use of GARCH analysis. The results suggested that futures' trading has a more volatile than spot market.

Stock returns volatility in the Tokyo stock exchange(2002), Y.K. Tse This paper examines the stock returns volatility in the Tokyo Stock Exchange. Structures of returns volatility are estimated and forecasted. The model of ARCH/GARCH and exponential weighted moving average (EWMA), this three tools used to measure the volatility of stock index future. The results show that the EWMA method gives the best forecasts. These findings have 
implications in forecasting movements of market volatility, with applications to option pricing and control for variation margin risk in stock index futures.

\section{Statement of the problem:-}

The research in derivatives market awareness is comparatively less in India, when compared to other developed countries. The globalization of financial markets have been increasing the large number of traders over the decade by providing a wide variety of market and trading investment options. However, it makes the trading investment decisions process much more complex. The investors generally consider their investment needs, goals, objectives and constraints while making investment decisions. But it is not possible for them to make a successful investment decision at all times. Their attitude is influenced by a variety of factors such as speculative income, get rich quickly strategy, stories of successful traders, online trading, investor derivatives awareness programme, etc. A better understanding of equity derivatives options strategies, valuation processes and outcomes are important for financial planners because an understanding of how traders generally respond to market movements would help them in devising appropriate asset allocation strategies for clients.

\section{Objectives of the Study:-}

$>$ The main objective of the study is to evaluate futures and options in equity derivatives of selected software companies of Infosys and TCS.

$>$ To find out the risk and return relationship in future and option contract

$>$ To have an in-depth awareness about future \& option market in India.

$>$ To assess risk management tools and its strategies.

$>$ To analyze the precariousness of Future and Option market.

\section{Scope for the Further Study:-}

$>$ The major scope of the study is to diminish the risk in derivatives and generate better returns in trading.

$>$ A derivative contract is the off-balance sheet financing so no records maintain for the future reference.

$>$ This study should spotlight on Future and option segment only so some changes happing in future.

$>$ The different participants also obtain good returns in derivatives contract i.e. Hedger, speculator, Arbitrageur.

\section{Limitations:-}

$>$ The study is based on secondary data and some inherent limitations of the secondary data would have exaggerated the study.

$>$ This study should focus on stock future and options on particular companies only.

$>$ The result of the investigation may change depending on the time period.

$>$ This study we have to consider only the short term decision making.

$>$ There is no stretchy trading in future contract because it is a standardized contract.

\section{Methodology of the study:-}

\section{a.) Sample Selection, Sample size and Period of the study}

$>$ Underlying asset of Infosys and Tcs stock futures and options to be used for the study

$>$ The availability of financial data required for calculating futures and options trading.

$>$ Underlying assets must be in National stock exchange in the derivatives segment

$>$ Selections of strike price have to be selected on contract's first day of options premium based on spot price.

$>$ The study covers three contacts ranging from April 2016 to June 2016

\section{Sources of Data:-}

The study is exclusively based on secondary data. The base price of the contracts on subsequent trading days will be the daily close price of the futures and options contracts. The major sources of data collected from the www.nseindia.com. 


\section{Tools Used for Analysis:-}

The statistical tools used to measures the futures and options price movements are; Risk (alpha \& beta), Return and Descriptive Statement Analysis.

Jensen's Alpha is a risk-adjusted performance benchmark that tells you by how much the returns of an actively managed portfolio of market returns.

Originating in the late 1960s, Jensen's Alpha (often abbreviated to Alpha) was developed to evaluate the skill of active fund managers in stock picking.

- A positive Alpha means that a portfolio has beaten the market, while a negative value indicates underperformance

- A fund manager with a negative alpha and a beta greater than one has added risk to the portfolio but has poorer performance than the market

Careful stock picking and financial engineering means that investors can add alpha to a portfolio without adversely affecting beta.

Jensen Model ALPHA is defined by this equation

Expressed as a formula:

$$
\begin{aligned}
& =\mathbf{R f}+\boldsymbol{\beta} \times(\mathbf{R m}-\mathbf{R f}) \\
& \text { Where: } \\
& \mathrm{Rm}=\text { Return on Market } \\
& \mathrm{Rf}=\text { risk free rate of return. } \\
& \beta=\text { Beta coefficient of portfolio }
\end{aligned}
$$

Beta describes the volatility of the portfolio with respect to that of the wider market, and is calculated with this equation

$$
\begin{aligned}
& \boldsymbol{\beta}=\mathbf{C o v}_{\mathbf{x y}} / \operatorname{Var}_{\mathbf{x}} \\
& \mathrm{x}=\text { Market Returns } \\
& \mathrm{y}=\text { Portfolio Returns }
\end{aligned}
$$

The market return is usually described by the expected return of an index, like the Nifty 50 Index.

\section{Returns:-}

Long

$$
\mathrm{R}_{\mathrm{t}}=\left(\mathrm{P}_{\mathrm{t}}-\mathrm{P}_{\mathrm{t}-1}\right) / \mathrm{P}_{\mathrm{t}-1} * 100 \text { or (Current Stock price }- \text { Previous day stock price)/ Previous day stock price*100) }
$$

\begin{tabular}{|c|c|c|c|c|c|c|}
\hline \multirow{4}{*}{ Long } & Month & Infosys Fut & TCS Fut & \multirow{4}{*}{ Short } & Infosys Fut & TCS Fut \\
\hline & April & 10.00 & 16.00 & & -9.00 & -16.00 \\
\hline & May & 7.40 & 2.30 & & -6.00 & -2.00 \\
\hline & June & -2.50 & -2.40 & & 3.20 & 2.70 \\
\hline
\end{tabular}

Short $=($ Current Stock price - Next day stock price $) /$ Next day stock price*100 $)$

$$
\begin{array}{ll}
\text { Where, } & \\
\mathrm{R}_{\mathrm{t}}= & \text { Return at the time } \\
\mathrm{P}_{=} & \text {The Closing price of the day } \\
\mathrm{P}_{\mathrm{t}-1}= & \text { The Closing price of the day } \mathrm{t}-1
\end{array}
$$

Descriptive Statement Analysis of daily return, standard deviation, Skewness Kurtosis Jarque-Bera test were analysed.

\section{Analysis and Interpretation:-}

\section{Return Analysis:-}

Return table for stock futures (Apr-Jun 2016) 


\section{Long \& Short Stock Futures Return for Infosys and TCS (April to June)}

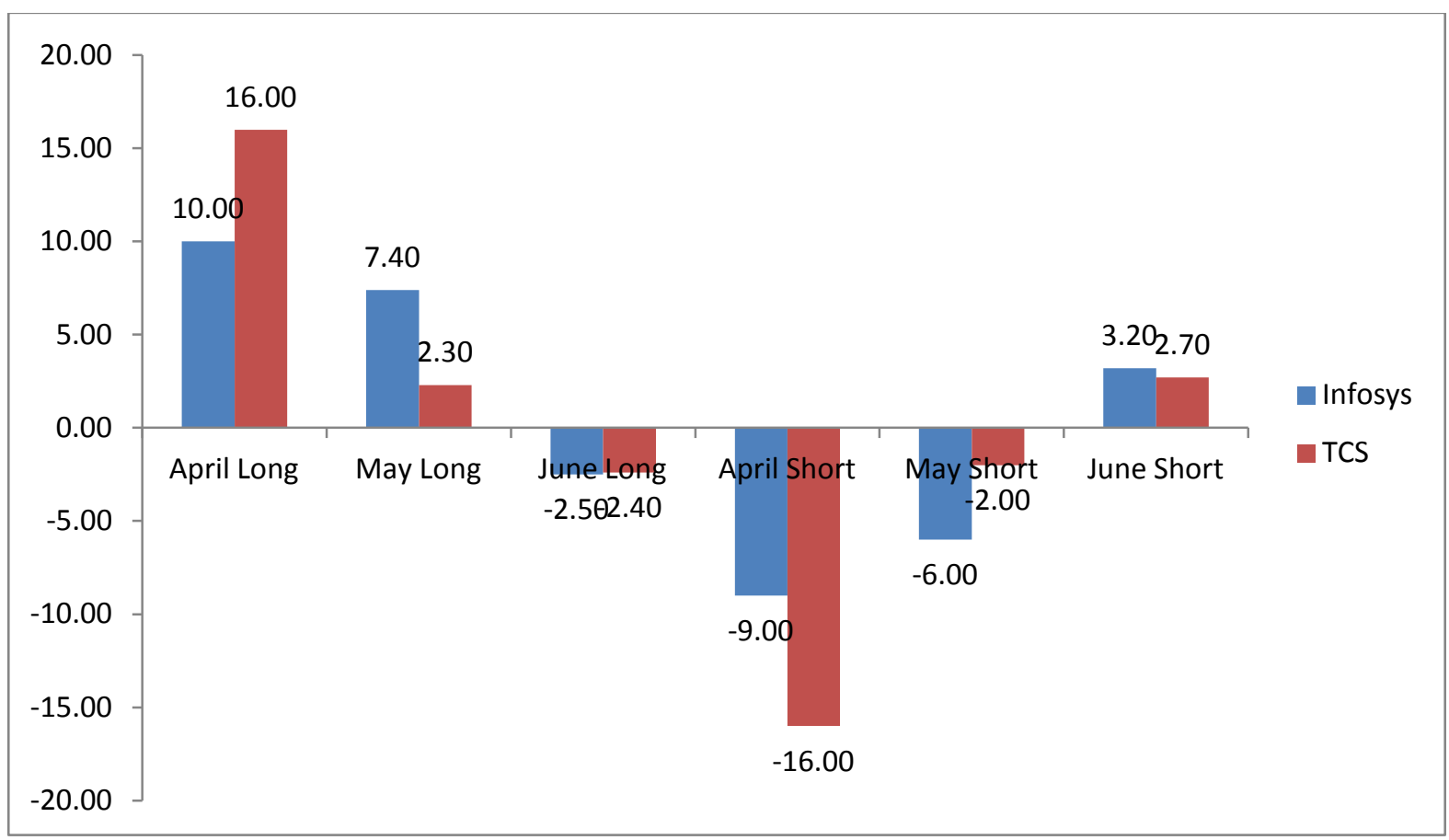

The above table indicates comparing the long and short return percentage of two software industries stock future of Infosys and TCS. This analysis indicates that TCS has maximum return in the month of April $2016(16 \%)$ and Infosys has maximum return in the month of April $2016(10 \%)$. At the same time short return percentage almost negative for the selected period with little positive return for both Infosys and TCS.

Return table for stock options (Apr-Jun 2016).

\begin{tabular}{|c|c|c|c|c|}
\hline \multicolumn{5}{|c|}{ Long } \\
\hline Month & Infosys CE & TCS CE & Infosys PE & TCS PE \\
\hline April & -3.36 & -8.10 & -18.45 & -11.99 \\
\hline May & -9.59 & -3.98 & -33.30 & -8.10 \\
\hline June & -15.19 & -7.47 & 77.20 & -7.70 \\
\hline \multicolumn{5}{|c|}{ Short } \\
\hline Month & Infosys CE & TCS CE & Infosys PE & TCS PE \\
\hline April & 25.78 & 10.17 & 88.34 & 82.04 \\
\hline May & 47.20 & 88.25 & 82.70 & 62.55 \\
\hline June & 5.00 & 75.25 & -59.20 & 11.17 \\
\hline
\end{tabular}




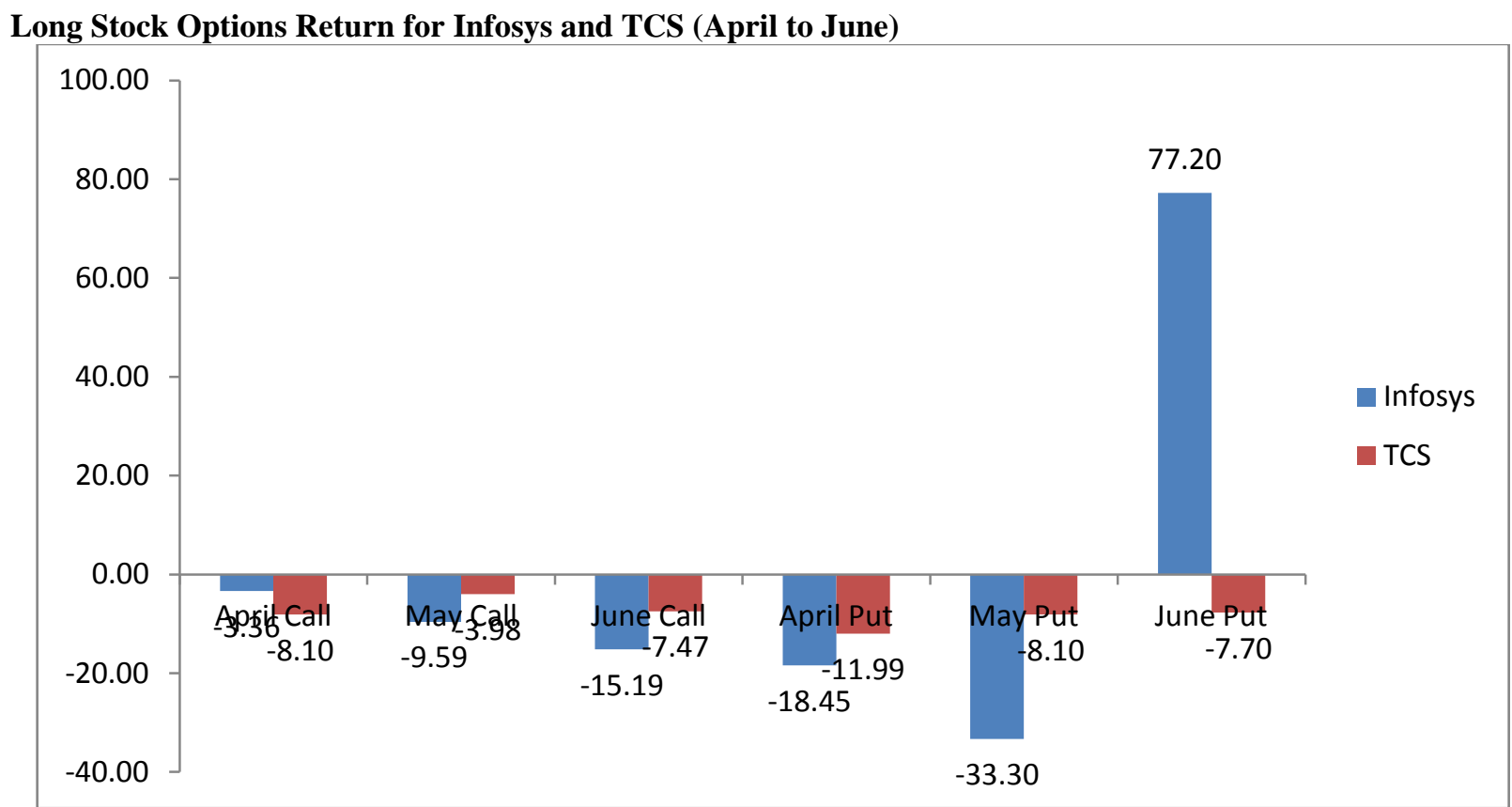

Short Stock Options Return for Infosys and TCS (April to June)

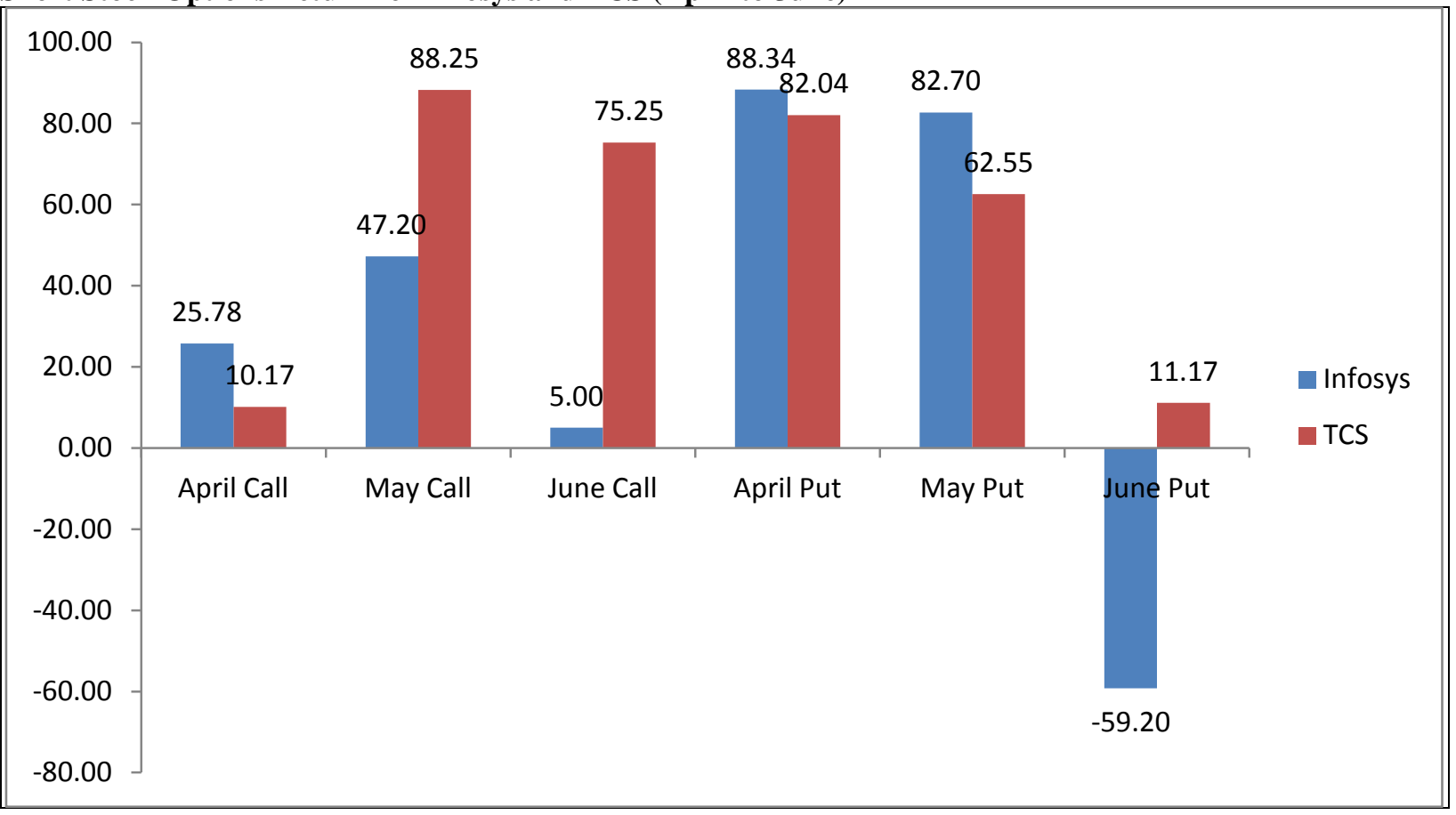

The stock option table indicates comparing the return percentage of Infosys and TCS, this opposite to futures return, long return percentage came with negative return at the same time short return stood with huge positive. This analysis indicates Infosys and Tcs showed maximum return in the month of April \& May $2016(88.34 \%$ \& 88.25\%) and only Infosys has down in the month of June put option. The above table indicates that short return has given more positive than long return because of mounting uncertainties for H1B Visa factor in software industries so inversely impacted. 
Risk Analysis (Alpha \& Beta):-

Alpha \& Beta table for Infosys \& TCS Futures (Apr - Jun 2016):

\begin{tabular}{|l|c|c|c|}
\hline \multicolumn{1}{|c|}{ Long } & Infosys -Tes Fut & Infosys -Tcs CE & Infosys -Tcs PE \\
\hline Beta & 0.65 & 0.46 & 2.20 \\
\hline Jensen Expected Return (ALPHA) & 1.24 & 0.88 & 4.16 \\
\hline \multicolumn{1}{|c|}{ Short } & 0.65 & 0.65 & 2.20 \\
\hline Beta & 1.24 & 5.47 & 4.56 \\
\hline Jensen Expected Return (ALPHA) & \multicolumn{3}{|l|}{} \\
\hline
\end{tabular}

ALPHA for Infosys and TCS (April to June).

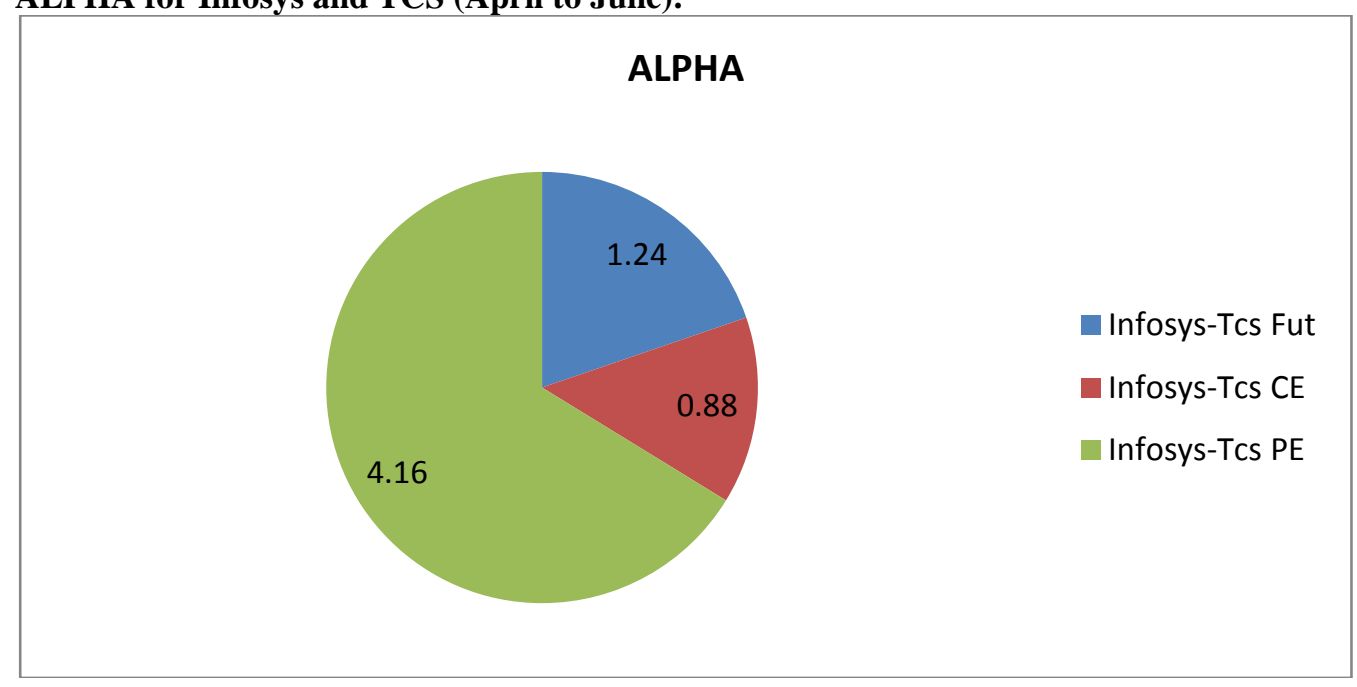

BETA for Infosys and TCS (April to June).

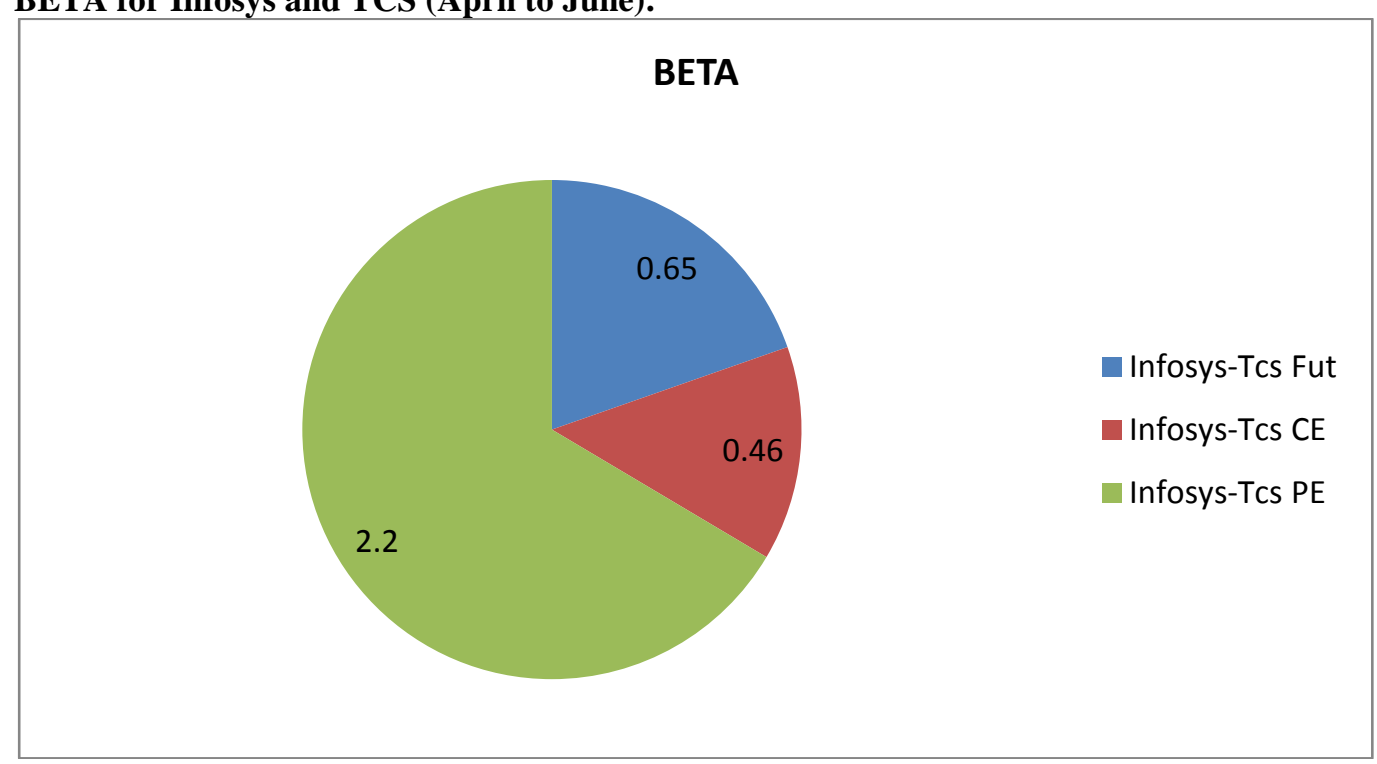

The positive alpha means the stock has over priced and the negative alpha means the stock has underpriced. Here both stock Infosys \& TCS has overpriced.

The beta of less than one means that the security prices will be less volatile than the market price. A beta of greater than 1 indicates that the security's price will be more volatile than the market. Here the beta of stock futures (.65) has less volatile than the market and the beta of stock option (2.20) has more volatile than the market. 
Descriptive Statement:-

Long Stock futures and options for Infosys \& TCS (Apr - Jun 2016)

\begin{tabular}{|l|c|c|c|c|c|c|c|}
\hline Long & $\begin{array}{c}\text { INFY_ } \\
\text { FUT }\end{array}$ & $\begin{array}{c}\text { INFY_OP_- } \\
\text { CE }\end{array}$ & $\begin{array}{c}\text { INFY_OP_ } \\
\text { PE }\end{array}$ & $\begin{array}{c}\text { MARKET_RET } \\
\text { URN }\end{array}$ & $\begin{array}{c}\text { TCS_F } \\
\text { UT }\end{array}$ & $\begin{array}{c}\text { TCS_OP_ } \\
\text { CE }\end{array}$ & $\begin{array}{c}\text { TCS_OP_ } \\
\text { PE }\end{array}$ \\
\hline Mean & -0.1384 & -0.4070 & 0.0928 & 0.0311 & 0.0341 & -0.1769 & -0.2818 \\
\hline Median & -0.1000 & -0.3600 & 0.0000 & 0.0300 & 0.0000 & -0.2700 & -0.3500 \\
\hline Std. Dev. & 0.2399 & 0.3730 & 0.7342 & 0.1333 & 0.1776 & 0.5408 & 0.4046 \\
\hline Maximum & 0.2900 & 0.3900 & 1.7900 & 0.3500 & 0.3900 & 0.9600 & 0.8300 \\
\hline Minimum & -0.6600 & -1.0000 & -1.0000 & -0.2200 & -0.3900 & -1.0000 & -1.0000 \\
\hline Skewness & -0.2958 & 0.1544 & 0.4647 & 0.3414 & -0.0463 & 0.3684 & 0.6009 \\
\hline Kurtosis & 2.2789 & 2.0473 & 2.3818 & 2.6696 & 2.4329 & 2.1910 & 3.0334 \\
\hline Jarque-Bera & 2.2111 & 2.5491 & 3.1671 & 1.4625 & 0.8391 & 3.0433 & 3.6741 \\
\hline Probability & 0.3310 & 0.2796 & 0.2052 & 0.4813 & 0.6574 & 0.2184 & 0.1593 \\
\hline observations & 61 & 61 & 61 & 61 & 61 & 61 & 61 \\
\hline
\end{tabular}

The above table presents the result of descriptive statistics of standard deviation, Skewness, Kurtosis and JarqueBera for Infosys and Tcs during the study period in the month of Apr - Jun 2016. It helps to summarize the overall performance of the business to understand the risk and reward of stock futures and options trading.

Descriptive Statement:-

Short Stock futures and options for Infosys \& TCS (Apr - Jun 2016)

\begin{tabular}{|c|c|c|c|c|c|c|c|}
\hline Short & $\begin{array}{c}\text { INFY_ } \\
\text { FUT }\end{array}$ & ${ }_{\text {CE }}^{\text {INFY_OP }}$ & $\begin{array}{c}\text { INFY_OP_ } \\
\text { PE }\end{array}$ & $\underset{\text { URN }}{\text { MARKET_RET }}$ & $\underset{\text { UT }}{\text { TCS_F }}$ & $\underset{\text { CE }}{\text { TCS_OP }_{-}}$ & $\underset{\text { PE }}{\text { TCS_OP }}$ \\
\hline Mean & 0.14 & 0.56 & -0.09 & -0.03 & -0.03 & 0.18 & 0.28 \\
\hline Median & 0.10 & 0.61 & 0.00 & -0.03 & 0.00 & 0.27 & 0.35 \\
\hline Std. Dev. & 0.24 & 0.48 & 0.73 & 0.13 & 0.18 & 0.54 & 0.40 \\
\hline Maximum & 0.66 & 1.58 & 1.00 & 0.22 & 0.39 & 1.00 & 1.00 \\
\hline Minimum & -0.29 & -0.51 & -1.79 & -0.35 & -0.39 & -0.96 & -0.83 \\
\hline Skewness & 0.30 & -0.25 & -0.46 & -0.34 & 0.05 & -0.37 & -0.60 \\
\hline Kurtosis & 2.28 & 2.36 & 2.38 & 2.67 & 2.43 & 2.19 & 3.03 \\
\hline Jarque-Bera & 2.21 & 1.65 & 3.17 & 1.46 & 0.84 & 3.04 & 3.67 \\
\hline Probability & 0.33 & 0.44 & 0.21 & 0.48 & 0.66 & 0.22 & 0.16 \\
\hline bservations & 61 & 61 & 61 & 61 & 61 & 61 & 61 \\
\hline
\end{tabular}

The above table presents the result of descriptive statistics of standard deviation, Skewness, Kurtosis and JarqueBera for Infosys and Tcs during the study period in the month of Apr - Jun 2016. It helps to summarize the overall performance of the business to understand the risk and reward of stock futures and options trading.

\section{Summary of Findings and Suggestions of the Study.}

Findings;-

The following are the major findings of the Study.

$>$ The study found that the highest return was gained from short positions in put options in the both the stocks.

$>$ Indian derivatives markets were more unstable throughout the study period.

$>$ From the above study illustrates the comparative return analysis of Infosys stock future and TCS stock future has maximum return in the month of April (10\% \& 16\%)

$>$ The comparative return analysis of Infosys \& TCS stock option has highest return in the month of May \& June $2016(88.34 \%$ \& $88.25 \%)$.

$>$ The comparative risk analysis of Stock Future \& option Infosys \& TCS has utmost minimum risk in stock option $0.46 \&$ less market volatility, the maximum risk in stock option is 2.20 \& more market volatility is 2.20 .

$>$ The stock futures volatility is normal of 0.65 . They are a lesser amount of volatile than market.

$>$ Descriptive statement explains that are constructive in summarizing data. 


\section{Suggestion:-}

The following are major suggestions of the study

$>$ The investors are advised to create the short positions in the beginning of the monthly contract of the selected Futures and options.

$>$ Trading positions should create beginning of the contract to capture the more premium with a view of the eroding in the end of the contract.

$>$ Normally, derivatives have certain risk so the investors should not take immediate investment decision and instead they should wait and watch the market movement.

$>$ This risk and return analysis helps the investors to take appropriate investment decision.

$>$ The Descriptive statement helps the investors invest their securities in the foremost company.

$>$ Updating of market information help the investors to get maximum return.

$>$ The investors should aware about the stock market conditions (e.g. Macro and micro data's monetary policy, GDP, inflation, war, social and political issues, currency fluctuation, etc.)

$>$ The study suggests that the Regulatory Authority (SEBI) must monitor the reliability or the truth of information released by Companies.

$>$ The present study suggests that whenever the performances of sectors declines in response to crisis announcement, the share holders should obtain instant decision either to buy or sell the stocks.

$>$ Investors should enter in to the market with right direction with view to gain potential return.

\section{Conclusion:-}

Investors need to see the overall on an average the value of beta and the value of expected returns. There are several different types of risks involved in financial derivatives transactions. Achieving the right balance between risk and return will ensure that traders achieve their financial goals with proper decisions. Risk in futures and options investment is about what might cause a loss of money on those investments. Deciding what risk is to take high or low as well as looking at chronological data are two examples of understanding risks and returns of future financial planning. The recent financial derivatives growth will definitely lead to boost the investors' self-belief in the Indian derivative market and carry an overall progress in all the segments of this market. Futures and Options traders need a very firm knowledge of the basics of Futures and options trading before even thinking of ways to make the money out of it. So, this article would give a broad outlook for the new investors to learn about the Futures and options trading in India.

\section{Books and Journals:-}

1. Chance Don M, Roberts Brooks, 2015, Introduction to Derivatives and Risk Management, 10th Edition, Cengage Learning.

2. Sundaram Janakiramanan, 2011, Derivatives and Risk Management, First Edition, Pearson.

3. Chew, Lilian, Managing Derivative Risk, John Wiley, New Jersey.

4. Madhumathi and Ranganatham, Derivatives and Risk Management, First Edition, Pearson, 2011

5. Hull J, Options, Futures and Other Derivatives, Prentice Hall of India, New Delhi.

6. Marshall, John F and V.K. Bansal, Financial Engineering - A Complete Guide to Financial Innovation, Prentice Hall of India, New Delhi.

7. M. Illueca, and J. A. Lafuente, 2003, "The effect of spot and futures trading on stock index market volatility", Volume 23, Issue 9, pages 841-858, September 2003.

8. Shafiqur Rahman, 2001, "The Introduction of Derivatives on the Dow Jones Industrial Average and Their Impact on the Volatility of Component Stocks", Volume 21, Issue 7, pages 633-653, July 2001, 'journal of financial market'.

9. Ramaprasad Bhar, 2001, "Return and Volatility Dynamics in the Spot and Futures Markets in Australia: An Intervention Analysis in a Bivariate EGARCH-X Framework", Volume 21, Issue 9, pages 833-850, September 2001.

10. Y.K. Tse, 2002, "Stock returns volatility in the Tokyo stock exchange", "report prepared by Tokyo stock exchange 2002'.

11. Harry M. Kat and Ronald C. Heynen, "Volatility Prediction: A Comparison of the Stochastic Volatility, GARCH $(1,1)$ and EGARCH $(1,1)$ Models", Journal of Derivatives, Vol.2, No.2, 1994, Cass Business School Research Paper, 'journal of financial market'

12. Janchung Wang, 2009, "Stock market volatility and the forecasting performance of stock index futures", Volume 28, Issue 4, pages 277-292, July 2009, 'journal of forecasting'. 
13. R. Glen Donaldson and Mark J. Kamstra, March 2000, "Forecasting Fundamental Stock Price Distributions", Simon Fraser University Working Paper No. 96- 2, Sauder School of Business Working Paper.

14. Jean-Philippe Peters (2001), "Estimating and forecasting volatility of stock indices using asymmetric GARCH models and (Skewed) Student-t densities".

15. Phil Holmes (2006), Stock index future hedging: Hedge ratio estimation, duration effects, expiration effects and Hedge ratio stability

16. Sathya Swaroop Debasish, "An Empirical Study onImpact of index future trading on spot market in India", KCA Journal of Business Management, Vol.2, issue 2(2009).

17. N.D. Vora \& Baghri (Tata McGraw-Hill) Options \& futures

18. Kolb, Robert W., Understanding Futures Markets, Prentice Hall of India, New Delhi. 